\title{
The Dynamics of Students' Mathematical Cognition Process in Solving Multitasking-based Problems: A Typical PISA Problem Used to Examine Students' Numerical Literacy
}

\author{
Titin F. Nisa ${ }^{1, *}$ I K. Budayasa ${ }^{2,}$ A. Lukito ${ }^{3,}$ Abadi Abadi ${ }^{4}$ \\ 1,2,3,4 Doctoral Program of Mathematics Education, Universitas Negeri Surabaya \\ *Corresponding author. Email: titinfaridatunnisa@trunojoyo.ac.id
}

\begin{abstract}
This study aimed to narrate the description of students' cognitive processes when completing multitasking-based problem-solving tasks. This study was qualitative-exploratory research. The research data was extracted through multitasking-based problem-solving tasks and the results of task-based interviews which were then analyzed qualitatively. The credibility of the data was checked by using the triangulation method. The research subjects were two people who were obtained through the process of selecting students with multitasking-based problem-solving tasks. The results obtained indicated that the students' cognitive process included four stages of the cognitive process, namely specializing, conjecturing, generalizing, and convincing. However, in the specializing stage, each subject showed different characteristics in terms of the problem-solving strategies used and the representations shown in communicating the results of their thoughts. The existence of this difference indicated that students' ability to use strategies depended on experience and practice, even the strategies themselves might become more abstract and complex. Thus, the results of this study were considered by teachers in determining learning models that were suitable for students' abilities.
\end{abstract}

Keywords: Cognition process, Multitasking, Problem-solving, Numerical literacy.

\section{INTRODUCTION}

The development of existing knowledge and technology requires students to have good working memory abilities that are closely related to student cognition. Cognitive processes are a person's mental processes that may be understood as information processing. Cognition is a person's ability to understand how something could happen, in the future, and consider it [1]. The process of student cognition may be seen through four processes, namely specializing, conjecturing, justifying, and generalizing [2]. Furthermore, other studies show the four cognitive processes in mathematical thinking, namely specializing, conjecturing, generalizing, and convincing [3], [4].

In general, cognitive processes may be improved through collaboration with elaboration, multimediabased learning, and the development of mathematical literacy. Conceptually, mathematical literacy development generally refers to mathematical cognitive competence. Standard competencies in learning mathematics according to some experts focus on problem-solving which reflects the emphasis on learning mathematics with understanding [5], [6]. In this case, there are two reasons that problem-solving is important given to students. The first is that mathematics worth learning is most closely represented in problem-solving tasks. The second is that students are more likely to engage in the mental activities necessary to develop understanding when they are exposed to mathematics embedded in problem situations [5]. Therefore, excellent problem-solving skills become an essential role for students to face the challenges in this era. On the other hand, someone who listens to it will have the opportunity to build knowledge from the results of listening to the explanation. Discussions that explore various mathematical ideas encourage someone to think more critically in building conceptual linkages. A student's 
ability to build the linkage of mathematical concepts can be through the tasks given, including multitasking task.

Multitasking ability needs to be owned by students. This is because, by having good multitasking abilities, children will be able to achieve targeted interventions efficiently. There are several descriptions of multitasking situations that can be found in everyday life. According to Jerry Linenger, the description of multitasking situations can be in the form of numerous tasks, one task at a time, interleaving required, delayed intentions, interruptions, differing task characteristics, and no feedback [7]. In real conditions, not all problems faced have all the characteristics of multitasking. It may be that only one or more of the multitasking characteristics are present in a given task. There is a lot of research on multitasking abilities. A person's ability to multitask can be viewed from the point of view of gender [8], [9], the use of multimedia in the learning environment [10], the condition of children with Attention Deficit Hyperactivity Disorder or ADHD [11], which in the application of multitasking may have a positive or negative impact [12], [13] are some relevant research in the area of multitasking. In some of these studies, the multitasking ability given is still general, not specifically in solving mathematical problems.

Research related to cognition and problem solving has also been carried out by several researchers, including studies related to students' cognitive processes in mathematical investigations based on gender differences [2], students' mathematical cognition processes through the provision of three kinds of games (Survivor, The Biggest Loser, and Deal or No Deal?) [4], students' cognitive processes in solving math problems for people with high functioning autism spectrum disorders [14]. From some of these studies, the cognition process observed with problem-solving problems is not based on multitasking. Some problem-solving problems given have the same category or several problem-solving tasks with different categories are given not at the same time. Further research, especially to solving multitasking-based problems was very needed to be implemented. In general, the purpose of this study is to determine the process of students' mathematical cognition in solving multitasking-based problems. The characteristics of multitasking situations in this study are found in the characteristics of different tasks.

\section{METHODS}

This study is exploratory research with a qualitative approach. The research data was obtained from the results of the subject's work on multitasking-based problem-solving tasks. In this study, researchers used a multitasking-based mathematical problem-solving task which was later called the Multitasking Ability Task (MAT). The research data was obtained from the results of the subject's work on the MAT and the results of taskbased interviews. The results of student work on the MAT are reviewed at the time of the interview. The interview data describes the process of the subject's cognition when completing the MAT. The interview process was documented using video/audio recordings. The results of students' work in completing the MAT identified the pattern of strategies used and the extent of the cognition process. Cognitive processes were tracked on two subjects with task-based interviews. The questions used in the interview include the exploration of the subject's work, confirmation of students' cognitive processes in completing the MAT, and clarification of the reason for the subject. Briefly, the research procedure can be seen in Figure 1.

\subsection{Participants}

In this study, the task of solving mathematical problems based on multitasking or MAT was given to 30 prospective participants in the Madrasah Science Competition or KSM in Bangkalan, East Java, Indonesia. From all the KSM participants, three people were able to complete MAT stage 1 with a score according to the minimum standard that had been determined, which was 80. After that, the three people were given coaching in understanding multitasking-based problem-solving tasks for 12 meetings. From the first to the eleventh meeting, the three selected people have explained the materials related to MAT. At the twelfth meeting, these three people were given MAT stage 2. Of the three people, only two people were able to complete according to the KSM standard and then these two people were selected as subjects in the study for in-depth interviews. These two subjects are called subject S1 and subject S2. S1 subjects are students aged 9 years with the highest score in MAT stage 2, while S2 subjects are students aged 11 years with second place scores in MAT stage 2.

\subsection{Instruments}

This MAT aimed to explore students' cognitive strategies and processes in completing assignments. This MAT had been validated by the validators. MAT was a collection of several mathematical problem-solving tasks adopting KSM questions at the district/city level. This was done by researchers because the types of questions in this KSM accommodate more than one type of problem-solving question. KSM questions consist of 3 characteristics of a multitasking situation differing task characteristics with the following details: (a) science questions that were integrated with Islam by exploring scientific concepts which should later be outlined in the questions in the Al Qur'an; (b) questions about science by exploring concepts and applications that existed in 
Islam, such as zakat, astronomy, and other themes related to science. This question was intended to make the students continue to study the concept of Islam with holistic science, and (c) questions of pure science. This question was carried out as an effort to keep madrasa students in line with other science Olympiad students.

In this study, if a given task arrangement contained more than one type of problem-solving task and was given at one time, then the assignment might be categorized as multitasking-based problem-solving. So, on this occasion, the KSM question used was one of the types of problem-solving based on multitasking. This was in line with one of the descriptions of multitasking problem situations in daily life according to Jerry Linenger, namely differing task characteristics [7].

The technical completion of this multitasking-based problem-solving task used the Think A Loud technique, which was to voice out loud what was being thought in solving multitasking-based problems. The content of mathematical problems contained in the MAT included problems of geometry, algebra, combinatorics, and integrated Islamic problems.

\subsection{Data Analysis}

The research data were analyzed by using six steps [15]. Firstly, it was preparing and organizing data. At this stage, the results of the subject's work were organized into two types, correct and incorrect answers. Secondly, the results of the subject's work were read and matched with a summary of the interview results related to the strategies used by the subject and the subject's cognition process in completing the MAT. Thirdly, it was describing the findings and forming a theme. Three themes were built from the content of mathematical problems in the MAT, namely problems of geometry, algebra, and combinatorics. Of the three themes, the researcher should explain the process of cognition in completing tasks on each subject. Fourthly, it was representing and reporting findings. At this stage, the researcher made tables, schematics of the structure of the cognitive process, and narratives to illustrate the findings. Fifthly, it was interpreting the meaning of the findings. Sixthly, it was validating the accuracy of the findings. To make it easier to present the data and report the findings of this study, the researcher used the rubric for scoring the cognitive process by adopting Lane and Harkness [4]. As for the credibility of the data by using triangulation methods, it was giving assignments (in the form of tests) and task-based interviews.

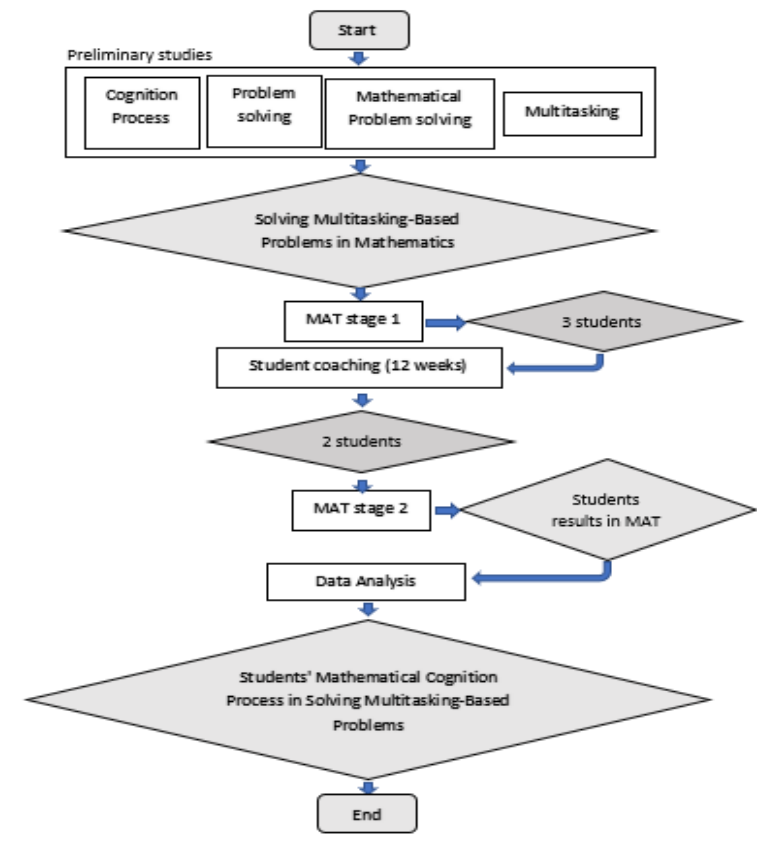

Figure 1 Research procedure flowchart.

\section{RESULTS AND DISCUSSION}

Scalar variables and physical constants should be italicized, and a bold (non-italics) font should be used for vectors and matrices. Italicized subscripts were prohibited unless they were variables. Equations should be either display (with a number in parentheses) or inline. the built-in Equation Editor or MathType was used to insert complex equations. Problem-solving was an activity that was carried out when students needed a way to overcome obstacles that aimed to answer questions or achieve goals. One's problem-solving abilities depended on the knowledge generated through representations. This might be seen when students were challenged to think and give reasons about mathematical ideas through representations (both visual and verbal) [16] and then communicate the results of their thoughts to others. Both writing and oral communication should be able to build meaning and strengthen the ideas that have been selfobtained when students solve problems, both monotask and multitask.

There were multiple task features in the multitasking design. The main features of multitasking included: separating tasks to try or complete, one task at a time, in between working on parts of the task, and switching to other parts of the task tasks without being reminded [7]. To understand the cognitive mechanisms involved in more complex multitasking scenarios, the Greenwich test was developed, which required the effective organization of tasks with various values and priorities [17]. Various aspects of multitasking performance were assessed, including the ability to memorize parts of the goals and rules of a task, form a plausible plan, follow the plan when performing tasks, complete goals without breaking 
the rules, recount one's performance, and remember parts

MAT from pure mathematics items and other types were

Table 1. Scoring results and analysis of Multitasking-Based Problem-Solving strategies

\begin{tabular}{|c|c|c|c|c|c|c|}
\hline \multirow{2}{*}{$\begin{array}{l}\text { Number } \\
\text { (Problems) }\end{array}$} & \multirow{2}{*}{ Subjects } & \multirow{2}{*}{ Strategy } & \multicolumn{4}{|c|}{ Score } \\
\hline & & & Specializing & Conjecturing & Generalizing & Convincing \\
\hline \multirow{2}{*}{$\begin{array}{c}1 \\
\text { (Geometry) }\end{array}$} & S1 & Logical reasoning strategy & 3 & 3 & 3 & 3 \\
\hline & $\mathrm{S} 2$ & Logical reasoning strategy & 3 & 3 & 3 & 3 \\
\hline \multirow{2}{*}{\begin{tabular}{|l}
\multicolumn{1}{c}{2} \\
(Integrated \\
Islamic \\
Geometry) \\
\end{tabular}} & S1 & $\begin{array}{l}\text { Making a drawing strategy and } \\
\text { logical reasoning }\end{array}$ & 3 & 3 & 3 & 3 \\
\hline & $\mathrm{S} 2$ & Logical reasoning strategy & 2 & 2 & 2 & 2 \\
\hline \multirow[t]{2}{*}{3 (Algebra) } & S1 & $\begin{array}{ll}\text { Formula-assisted } & \text { logical } \\
\text { reasoning strategy } & \\
\end{array}$ & 2 & 3 & 3 & 3 \\
\hline & S2 & $\begin{array}{l}\text { Logical reasoning and organizing } \\
\text { data }\end{array}$ & 2 & 3 & 3 & 3 \\
\hline \multirow{2}{*}{\begin{tabular}{|c}
\multicolumn{1}{c}{4} \\
(Integrated \\
Islamic Algebra)
\end{tabular}} & S1 & $\begin{array}{ll}\text { Formula-assisted } & \text { logical } \\
\text { reasoning strategy } & \\
\end{array}$ & 2 & 2 & 3 & 3 \\
\hline & S2 & $\begin{array}{l}\text { Logical reasoning and finding a } \\
\text { pattern }\end{array}$ & 2 & 2 & 3 & 3 \\
\hline \multirow{2}{*}{$\begin{array}{c}5 \\
\text { (Combinatorics) }\end{array}$} & S1 & $\begin{array}{l}\text { Logical reasoning strategy and } \\
\text { finding a pattern }\end{array}$ & 2 & 3 & 3 & 3 \\
\hline & $\mathrm{S} 2$ & Does not respond & 1 & 1 & 1 & 1 \\
\hline \multirow{2}{*}{\begin{tabular}{|l|}
\multicolumn{1}{|c|}{6} \\
(Integrated \\
Islamic \\
Combinatorics)
\end{tabular}} & S1 & Logical reasoning strategy & 2 & 3 & 3 & 3 \\
\hline & S2 & Organizing data by creating a list & 2 & 3 & 3 & 3 \\
\hline
\end{tabular}

of the goals and rules afterward [18].

Three important cognitive constructs underpin multitasking: retrospective memory, planning, and prospective memory. Retrospective memory referred to remembering past information (e.g., memory for words and experiences people have had in the past) and helping to memorize and retain rules and goals in multitasking scenarios. Planning referred to the cognitive process of forming thoughts to achieve goals and helps in making optimal arrangements for various tasks with varying priorities. Prospective memory was defined as the ability to implement delayed intentions on one's initiative and, there are three aspects of performance in multitasking: plan compliance, task goal completion without breaking rules, and the ability to recalculate one's performance afterward [7]. Thus, in the Burgess model, retrospective memory played a fundamental and supportive role in planning and prospective memory and was even considered a precursor to prospective memory.

Disclosure of the profile of students' cognitive processes in the MAT was seen based on the results of the work of two research subjects in completing the MAT which included 4 stages, namely the process of specializing, conjecturing, generalizing, and convincing [4]. It was obtained that the S1 subject tended to do the done later. Based on the results of interviews with undergraduates, questions with the type of pure mathematics might be done directly without having to remember the relevance of Islamic concepts first, so that they were faster in working. While S2 subjects tended to work following the order of the questions given. When the subject of S2 had difficulty, the subject of S2 continued to the next item. If there was still time left, the subject of S2 should review the items that had been missed. The data obtained from the results of task-based multitasking problem solving and task-based interviews were analyzed to describe students' cognitive processes and strategies used when solving these problems. The following Table 1 presents the details of the work of the subject of S1 and S2 subjects in completing the MAT.

Based on Table 1, it was illustrated that the students' cognitive process when solving geometric problems both subjects used the same strategy in solving the problem. The strategy used was to directly work on problemsolving calculations with logical reasoning. This logical reasoning strategy was a suitable strategy to explore how to reason in formal reasoning and everyday reasoning tasks [19]. S1 and S2 subjects performed the specializing process. The subject responded by examining certain data or information in the problem and manipulating it using correct mathematics. At the conjecturing stage, S1 and S2 
subjects explored possible relationships that were examined in the specializing process. For the generalizing process, the subject of S1 and S2 made generalizations based on the process of specializing and conjecturing. For the convincing process, both subjects gave convincing arguments to support the generalizations that had been made and by using correct mathematical calculations. In this geometry problem, both subjects tended to use symbolic representations in communicating the results of their thoughts.

In the second item, the subject solves the problem of integrated Islamic geometry, which was a question that contained mathematical problems in an Islamic context [20]. When solving the problem of integrated Islamic geometry, there was a concept of Islamic integration related to the concept of the order of the Prophet Zulkifli AS in the order of 25 prophets and apostles. The students' cognitive process might be described that the subjects of $\mathrm{S} 1$ and $\mathrm{S} 2$ provided different strategies. In the specializing process, the subject of S1 used a drawing strategy with 3 stationeries, a black pen, a red pen, and a pencil on a rectangular image, then $\mathrm{S} 1$ used a logical reasoning strategy to solve it. The $\mathrm{S} 1$ subject performed the specializing process with the response by examining the data that manipulated it with the correct mathematics. While the S2 subject responded by examining certain data or information in the problem and manipulating it using incorrect mathematics. At the conjecturing stage, the response given by the $\mathrm{S} 1$ subject gave a response to exploring with the evidence used containing correct mathematics. While the S2 subject began to explore possible relationships that were examined in the specializing process. For the generalizing process, the subject of S1 made generalizations based on the process of specializing and conjecturing. While the subject of S2 showed the generalization given was not clear because the subject of S2 was a bit doubtful about the calculation process that had been carried out. For the convincing process, subject S1 provided convincing arguments to support the generalizations that had been made and by using correct mathematical calculations. While the subject of S2 showed that the response given contained incorrect mathematics. In solving the problem of integrated Islamic geometry, the undergraduate subject used two representations, both symbolic and pictorial while $\mathrm{S} 2$ subjects tended to use symbolic representations.

Algebra problems were one of the everyday reasoning tasks, so most students solved problems using logical reasoning strategies [19]. In the algebraic problem, the description of the cognitive process of the S1 and S2 subjects used the same strategy, namely logical reasoning. In the specializing process, $\mathrm{S} 1$ and $\mathrm{S} 2$ subjects might respond to answers using one way and demonstrate the correct use of mathematics. In the conjecturing process, subjects S1 and S2 could explore, discuss, and strengthen relationships and patterns. In this process, subject S1 used the formula for the number of nth syllables, while subject S1 calculated directly the sum of all numbers that represented the word "TERJAMUR". In the generalizing process, the subject of S1 and S2 might provide clear generalizations and follow the process of specializing and conjecturing. At the convincing stage, subjects S1 and S2 might provide convincing arguments to support generalization and use correct mathematics. In solving this algebraic problem, the subjects of S1 and S2 used a symbolic representation. However, S1 subjects tended to use formula-assisted logical reasoning, while S2 subjects used logical reasoning and organize data.

While in solving the problem of integrated Islamic algebra, namely the concept of integration of Islamic context [20] that was raised was the Tajwid reading which was related to the number of idgham bighunnah letters and Izhar letters, the process of cognition of S1 subjects used a formula-assisted logical reasoning strategy while the S2 subject uses logical reasoning and finding a pattern. In the specializing process, the subject of S1 and S2 responded by showing evidence using one method and using the correct mathematics. In the conjecturing process, subjects S1 and S2 had explored, discussed, strengthened relationships and patterns. In this process, S2 was able to show in more detail. In the generalizing process, $\mathrm{S} 1$ and $\mathrm{S} 2$ subjects were able to make clear generalizations and follow directly from the specializing and conjecturing process. In the convincing process, the subject might provide convincing arguments to support the generalizations made and use correct mathematics. In solving the problem of integrated Islamic algebra, both subjects tended to use symbolic representations to communicate the results of their thoughts.

In solving the combinatorics problem, the description of the cognitive process of the undergraduate subject used a logical reasoning strategy and finding a pattern. While the subject of S2 did not provide an answer on the grounds of not knowing how to solve it. This shows that in the specializing process, the subject of S1 was able to show evidence by using one method and using the correct mathematics while the subject of S2 was unable to show evidence of problem-solving examination. In the conjecturing process, the S1 subject was able to explore, discuss, and strengthen relationships and patterns in the specializing process. While S2 was not able to show evidence of any relationship or pattern in the specializing process. In the generalizing process, the $\mathrm{S} 1$ subject showed a score of 3 as the subject might provide a clear generalization statement and follow directly from the specializing and conjecturing process while the S2 subject was not able to provide a generalization statement from the specializing and conjecturing process. In the convincing process, the subject of S1 was able to provide convincing arguments to support the generalizations that had been made and used correct mathematics. While the subject of S2 made no effort to provide convincing arguments regarding generalizations. In solving this 
combinatorics problem, the S1 subject used logical reasoning strategies and found a pattern. In solving this problem, the $\mathrm{S} 1$ subject used symbolic representations to show the results of his thoughts [21].

Meanwhile, in solving the problem of integrated Islamic combinatorics, it was by knowing the names of religious books taught in elementary education which consisted of the Aqidatul Awam, Amtsilah AtTashrifiyah, Al Ajurumiyah, and Safinatun Najah books. The description of the cognitive process of S1 and S2 subjects used different strategies. In the specializing process, the subject of $\mathrm{S} 1$ and $\mathrm{S} 2$ was able to show evidence by using one method and using the correct mathematics. S1 subjects used logical reasoning strategies with the help of multiplication rules. While the S2 subject used a data organizing strategy by creating a list (making a list) of all the possibilities that might happen. In the conjecturing process, S1 and S2 subjects were able to explore, discuss relationships and patterns in the specializing process. In the generalizing process, S1 and S2 subjects were able to provide a clear generalization statement and followed directly from the specializing and conjecturing process. In the convincing process, subjects S1 and S2 showed a score of 3, namely the subject was able to provide convincing arguments to support the generalizations that had been made and used correct mathematics. In solving the problem of integrated Islamic combinatorics, the two subjects used symbolic representations by symbolizing each book's name with symbols of numbers $1,2,3$, and 4 respectively. This symbolic representation was used to show their selves mathematical objects and processes [21].

Based on the results of data analysis, the research subjects used 4 stages of the cognitive process in solving multitasking-based problems, namely the process of specializing, conjecturing, generalizing, and convincing. This is in line with the research of Subarinah et al [2] and Lane and Harkness [4]. Analogous with the assignment with investigations, processes, and activities carried out and determining alternative characterizations of the investigation process from the pattern of its core cognitive processes, namely specializing, conjecturing, justifying, and generalizing [22]. It only differed in the mention of the terms convincingly with justification. While the strategies used by the two subjects in this study were of several kinds, including logical reasoning strategies, making a drawing, making a pattern, and organizing data by creating a list. These strategies were some of the strategies used in mathematical investigations. This multitasking-based problem solving was part of the mathematical investigation and was a problem for students. This is because a problem was a situation faced by students, which required resolution, and in which the path to the answer was not immediately known [23].

Based on the results of the description of the research results, the subject of $\mathrm{S} 1$ showed a person who tended to have serialist characteristics. This was because S1 subjects tended to use algorithmic thinking. While S2 subjects tended to have holistic characteristics because S2 subjects tended to look at the problem as a whole and found patterns from the given problem. This result was in line with the previous work which shows that there was two student learning styles in the learning process and problem-solving, namely holistic and serialist [24]. This result also corresponded with another study exhibits that in the process of solving mathematical problems, someone with a serialist thinking style, when doing the sensory register, his attention and perception were good so that information was stored in short term memory, retrieval was done well, information had been stored properly in long term memory, and coding was well done. Meanwhile, someone with a holistic thinking style lacked attention and unstructured perception so that information was not stored properly in short-term memory. Therefore, at the time of rehearsal, they had difficulty in applying certain methods because the information was not stored properly in the long-term memory [25].

In this study, the subjects had differences in representing the results of their thinking when solving problems. Both subjects tended to represent the results of their thoughts using symbolic representations. S1 subjects sometimes used two external representations at once, namely symbolic and pictorial representations to make it easier to explore the problem-solving ideas used. This shows that in this study the subject only used two types of external representations from the three types of external representations that exist, namely verbal representations, pictorial representations, and symbolic representations [21]. As with Gestalt theory, one's understanding of problem-solving was carried out in an organized manner. The information presented in problem-solving has a sequential pattern. When a person performed a problem-solving procedure, he should use representations to present information in imaginative visual terms [26].

In this study, both subjects used the Polya problemsolving procedure. Both subjects solved problems based on multitasking done by following Polya's steps, namely understanding the problem, making plans, carrying out plans, and looking back [27]. Both subjects followed Polya's heuristic model as a problem-solving plan. In this study, the two subjects tried various approaches to find a solution to a problem as done by Thohir et al [28] and Posamentier and Krulik [23]. Students should first read the problem and think about it. He should carefully identify what information was provided and what was found. Redundant information is removed. Next, the 
student decides on a plan. A strategy was suggested to be used in solving the problem. In the third stage, students applied the chosen strategy and tried to solve the problem, so that they arrived at the correct answer. However, only until the third step was carried out by the two subjects. They did not do the fourth step because they were sure of the idea and the calculation process that had been done. So, they moved on to the next problem to be solved without re-checking the process of understanding the problem, finding problem-solving ideas, and also the calculations carried out.

In this study, the subjects had different ages, namely the 9-year-old subject and the 11-year-old subject. As with the multitasking study, the ability to stick to plan developed slowly, and both subjects benefited from practice during the coaching process. Children aged 9 years did not have good planning skills, so children tended to be random or less systematic in communicating the results of problem-solving. Meanwhile, children aged 11 years had better planning skills, so that in communicating the results of their thoughts, children tended to be more organized and systematic despite the effects of exercise. This is in line with relevant research, that planning skills developed slowly and showed the effect of exercise for older children but not for younger children [15]. Referring to Bloom's taxonomy theory, 9year-olds are at high-level C3 (apply), 10-year-olds are at level C3 through C5 (evaluate) but are still limited, and 11-year-olds are at level C4 through C6 (create) [29].

\section{CONCLUSION}

Based on the results of the study, it can be concluded that the students' mathematical cognition process in solving multitasking-based problems used four stages. Subjects with higher multitasking-based problem-solving skills had greater diversity in the use of problem-solving strategies compared to subjects with lower multitaskingbased problem-solving abilities. There are differences in the representations shown by the two subjects when communicating the results of multitasking-based problem-solving. Future research is expected to be carried out with a variety of different multitasking problem situations so that it may describe in more detail the students' cognitive processes in various multitasking conditions.

\section{AUTHORS' CONTRIBUTIONS}

All authors conceived and designed this study. All authors contributed to the process of revising the manuscript, and at the end all author have approved the final version of this manuscript.

\section{ACKNOWLEDGMENTS}

The researcher would like to thank Universitas Negeri Surabaya and Madrasah Ibtidaiyah Negeri 1 Bangkalan for supporting facilities this work.

\section{REFERENCES}

[1] K.W. Jones, Communication and Collaboration Cognition Systems: A Sociological Process for Integrating Standalone Technologies with the Global Information Grid, in: Natl. Aerosp. Electron. Conf. Proc. IEEE, 2008, pp. 10-19. DOI: $10.1109 /$ NAECON.2008.4806508

[2] S. Subarinah, I.K. Budayasa, A. Lukito, Cognitive Processes of Elementary School Students in Mathematical Investigation Based on Gender Difference, in: Proceeding Int. Conf. Res. Implement. Educ. Math. Sci., May 2014, pp. 1820.

[3] L. Burton, Mathematical Thinking: The Struggle for Meaning, in: Journal for Research in Mathematics Education, vol. 15, no. 1, 1984, pp. 35-49. DOI: 10.5951/jresematheduc.15.1.0035

[4] C.P. Lane, S.S. Harkness, Game show mathematics: Specializing, conjecturing, generalizing, and convincing, in: Journal of Mathematical Behavior, vol. 31, no. 2, 2012, pp. 163-173. DOI: 10.1016/j.jmathb.2011.12.008

[5] E. Fennema, T.A. Romberg, Mathematics Classrooms that Promote Understanding, in: The Studies in Mathematical Thinking and Learning Series, A. Sierpinska, Ed. New Jersey: Lawrence Erlbaum, 1999, pp. 204.

[6] A.H. Schoenfeld, Learning to Think Mathematically: Problem Solving, Metacognition, and Sense Making in Mathematics (Reprint), in: Journal of Education, vol. 196, no. 2, 2016, pp. 1-38. DOI: $10.1177 / 002205741619600202$

[7] P.W. Burgess, Real-World Multitasking from a Cognitive Neuroscience Perspective, in: Control of Cognitive Processes, vol. 18, January 2000, pp. 465-472.

[8] T. Mäntylä, Gender Differences in Multitasking Reflect Spatial Ability, 2013. DOI: $10.1177 / 0956797612459660$

[9] D. Ren, A Deeper Look at Gender Difference in Multitasking: Gender-Specific Mechanism of Cognitive Control, 2009, pp. 13-17. DOI: 10.1109/ICNC.2009.542 
[10] M.L. Courage, A. Bakhtiar, C. Fitzpatrick, S. Kenny, K. Brandeau, Growing up multitasking: The costs and benefits for cognitive development, in Developmental Review, vol. 35, 2015, pp. 541. DOI: $10.1016 / j . d r .2014 .12 .002$

[11] S. Siklos, K.A. Kerns, Assessing multitasking in children with ADHD using a modified Six Elements Test, in: Arch. Clin. Neuropsychol. 19, vol. 19, 2004, pp. 347-361. DOI: 10.1016/S08876177(03)00071-4

[12] P. Cardoso-leite, C.S. Green, D. Bavelier, On the impact of new technologies on multitasking, in: Developmental Review, vol. 35, 2015, pp. 98112. DOI: $10.1016 /$ j.dr.2014.12.001

[13] S.C. Otto, K.R. Wahl, C.C. Lefort, W.H.P. Frei, Exploring the Impact of Multitasking In the Workplace, in: Journal of Business Studies Quarterly, vol. 3, no. 4, 2012, pp. 154-162.

[14] N. Fauziyah, C.L. Lant, I.K. Budayasa, D. Juniati, Cognition processes of students with high functioning autism spectrum disorder in solving mathematical problems, in: International Journal of Instruction, vol. 12, no. 1, 2019, pp. 457-478. DOI: $10.29333 / \mathrm{iji} .2019 .12130 \mathrm{a}$

[15] J.W. Creswell, Research Design: Qualitative, Quantitative, and Mixed Methods Approaches, Fourth Edi. California: Sage Publication, Inc, 2014.

[16] D.P. Sari, Darhim, R. Rosjanuardi, Errors of students learning with react strategy in solving the problems of mathematical representation ability, in: Journal on Mathematics Education, vol. 9, no. 1, 2018, pp. 121-128. DOI: 10.22342/jme.9.1.4378.121-128

[17] P.W. Burgess, Strategy Application Disorder: The Role of the Frontal Lobes in Human Multitasking, in: Psychological Research, vol. 63, Agustus, 2000, pp. 279-288. DOI: $10.1007 / \mathrm{s} 004269900006$

[18] T. Yang et al., The Development of Multitasking in Children Aged 7 - 12 Years : Evidence from Cross-Sectional and Longitudinal Data, in: Journal of Experimental Child Psychology, vol. 161, 2017, pp. 63-80. DOI: 10.1016/j.jecp.2017.04.003

[19] H. Bronkhorst, G. Roorda, C. Suhre, M. Goedhart, Logical Reasoning in Formal and Everyday Reasoning Tasks, in: International Journal of Science and Mathematics Education, vol. 18, no. 8, 2020, pp. 1673-1694. DOI: 10.1007/s10763019-10039-8
[20] M. Fatra, M.A. Jatmiko, The ability of" HOTS" mathematics with an Islamic context in Madrasah Tsanawiyah Students based on TIMSS design, September. 2021.

[21] J.L. Villegas, E. Castro, J. Gutiérrez, Representations in Problem Solving: A Case Study with Optimization Problems, in: Electronic Journal of Research in Educational Psychology, vol. 7, no. 17, 2009, pp. 279-308.

[22] J.B. Yeo, B.H. Yeap, Characterising the Cognitive Processes in Mathematical Investigation, in: International Journal for Mathematics Teaching and Learning, vol. 11, 2010, pp. 10, 2010, [Online].

Available: http://libaccess.mcmaster.ca/login?url=http://sear ch.proquest.com/docview/822506743?accountid $=12347 \% 5 \mathrm{Cnhttp}: / / \mathrm{sfx}$.scholarsportal.info $/ \mathrm{mcma}$ ster?url_ver=Z39.88-

2004\&rft_val_fmt=info:ofi/fmt:kev:mtx:journal \&genre=article\&sid=ProQ:ProQ:ericshell\&atitle $=$ Charac.

[23] A.S. Posamentier, S. Krulik, Problem Solving in Mathematics Grades 3-6: Powerful Strategies to Deepen Understanding. California: CORWIN, 2009.

[24] N. Bajraktarevic, W. Hall, P. Fullick, Incorporating Learning Styles in Hypermedia Environment: Empirical Evaluation, in: Proceedings of the Workshop on Adaptive Hypermedia and Adaptive Web-Based System, no. 1999, 2003, pp. 41-52. [Online]. Available: http://citeseerx.ist.psu.edu/viewdoc/download?do $\mathrm{i}=10.1 \cdot 1.112 .5045 \& \mathrm{rep}=\mathrm{rep} 1 \&$ type $=$ pdf

[25] A.W. Yanti, Kusaeri, M. Kustianingsih, Profile of Cybernetic Thinking of Students in Mathematical Problem Solving Based on Serialist and Holist Thinking Style, in: JTAM, vol. 4, no. 2, 2020, pp. 122-132.

[26] R.L. Solso, O.H. Maclin, K. Maclin, Cognitive Psychology 8th Edition, 2014.

[27] G. Polya, How to Solve It. A New Aspect of Mathematical Method., Second Edition, New Jersey: Princeton University Press, 1985.

[28] M. Tohir, Susanto, H. Hobri, Suharto, Dafik, Students' Creative Thinking Skills in Solving Mathematics Olympiad Problems Based on Problem-Solving Polya and Krulik-Rudnick Model, in: Advanced Science Letters, vol. 24, no. 11, November 2018, pp. 8361-8364. DOI: 10.1166/asl.2018.12563

[29] C. Bereiter, Beyond Bloom's Taxonomy: Rethinking Knowledge for the Knowledge Age, pp. 5-22, 2005. 